BMC

Nephrology

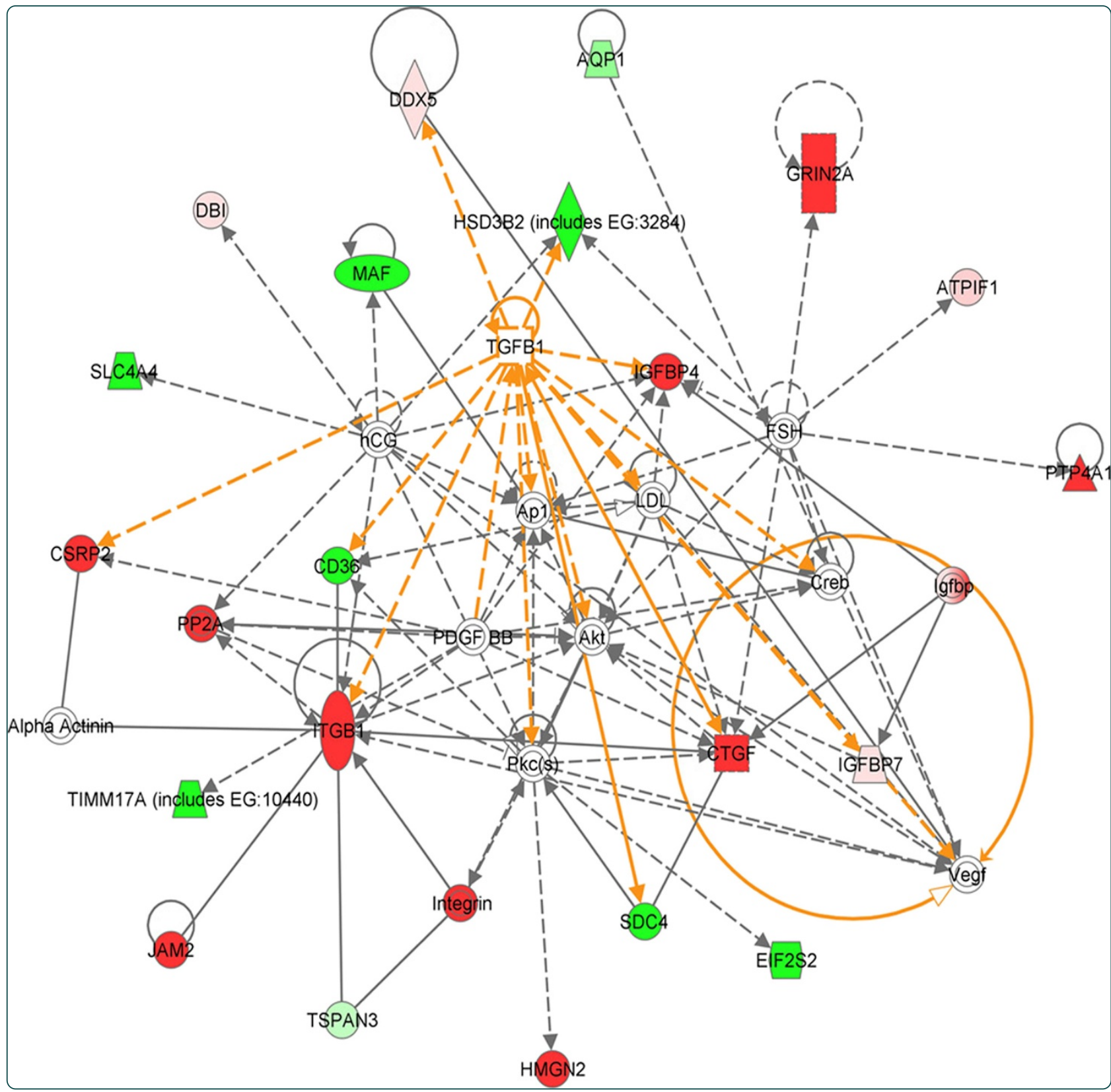

\title{
Identification of nephropathy candidate genes by comparing sclerosis-prone and sclerosis-resistant mouse strain kidney transcriptomes
}

El-Meanawy et al. 


\title{
Identification of nephropathy candidate genes by comparing sclerosis-prone and sclerosis-resistant mouse strain kidney transcriptomes
}

\author{
Ashraf El-Meanawy ${ }^{4}$, Jeffery R Schelling ${ }^{1}$, Sudha K Iyengar ${ }^{2}$ Patrick Hayden', Shrinath Barathan ${ }^{1}$,
} Katrina Goddard², Fatima Pozuelo ${ }^{1}$, Essam Elashi ${ }^{1}$, Viji Nair ${ }^{3}$, Matthias Kretzler ${ }^{3}$ and John R Sedor ${ }^{{ }^{* *}}$

\begin{abstract}
Background: The genetic architecture responsible for chronic kidney disease (CKD) remains incompletely described. The Oligosyndactyly (Os) mouse models focal and segmental glomerulosclerosis (FSGS), which is associated with reduced nephron number caused by the Os mutation. The Os mutation leads to FSGS in multiple strains including the ROP-Os/+. However, on the C57BI/6J background the mutation does not cause FSGS, although nephron number in these mice are equivalent to those in ROP-Os/+ mice. We exploited this phenotypic variation to identify genes that potentially contribute to glomerulosclerosis.
\end{abstract}

Methods: To identify such novel genes, which regulate susceptibility or resistance to renal disease progression, we generated and compared the renal transcriptomes using serial analysis of gene expression (SAGE) from the sclerosis-prone ROP-Os/+ and sclerosis resistant C57-Os/+ mouse kidneys. We confirmed the validity of the differential gene expression using multiple approaches. We also used an Ingenuity Pathway Analysis engine to assemble differentially regulated molecular networks. Cell culture techniques were employed to confirm functional relevance of selected genes.

Results: A comparative analysis of the kidney transcriptomes revealed multiple genes, with expression levels that were statistically different. These novel, candidate, renal disease susceptibility/resistance genes included neuropilin2 (Nrp2), glutathione-S-transferase theta (Gstt1) and itchy (Itch). Of 34 genes with the most robust statistical difference in expression levels between ROP-Os/+ and C57-Os/+ mice, 13 and 3 transcripts localized to glomerular and tubulointerstitial compartments, respectively, from micro-dissected human FSGS biopsies. Network analysis of all significantly differentially expressed genes identified 13 connectivity networks. The most highly scored network highlighted the roles for oxidative stress and mitochondrial dysfunction pathways. Functional analyses of these networks provided evidence for activation of transforming growth factor beta (TGF $\beta$ ) signaling in ROP-Os/+ kidneys despite similar expression of the TGF $\beta$ ligand between the tested strains.

Conclusions: These data demonstrate the complex dysregulation of normal cellular functions in this animal model of FSGS and suggest that therapies directed at multiple levels will be needed to effectively treat human kidney diseases.

\footnotetext{
* Correspondence: john.sedor@case.edu

'Department of Medicine, MetroHealth System, Case Western Reserve

University, Cleveland, OH, USA

Full list of author information is available at the end of the article
} 


\section{Background}

Focal segmental glomerulosclerosis (FSGS) is a leading cause of nephrotic syndrome in adults and is particularly prevalent in the African American population [1-3]. The incidence of FSGS is increasing in young children $[4,5]$. Immunosuppressive therapies are the mainstay of treatment, though most patients with FSGS are resistant to treatment [6]. Unfortunately, a large proportion of FSGS patients, who do not respond to treatment, frequently continue to lose kidney function and progress to end stage renal disease (ESRD), requiring dialysis or kidney transplantation. Moreover, recurrent FSGS is a leading cause of proteinuria and allograft loss after kidney transplantation [7-9].

In recent years, genes have been linked or associated with both familial and sporadic FSGS [10-16], which supports the premise that genetic factors play a major pathophysiologic role [17]. To identify novel, candidate FSGS susceptibility genes, we used Serial Analysis of Gene Expression (SAGE) to characterize the kidney transcriptome in the Oligosyndactyly $(O s)$ mouse, a genetic model of oligomeganephronia and progressive FSGS. Homozygous Os/Os mice die in utero at the 64-cells stage of development [18], but heterozygote Os/+ mice have a skeletal phenotype mainly in the form of fused digits (oligosyndactyly), and a renal phenotype in the form of $50 \%$ reduction in nephron number $[19,20]$. The ROP/GnLe strain (ROP-Os/+), was established at the Jackson Lab and has been maintained by sibling mating. As the ROP-Os/+ mice age, they develop a histopathologic lesion similar to human FSGS. The Os mutation causes on average 50\% reduction of nephron number, an effect which is independent of genetic background. The ROP-Os/+ mice model progressive kidney disease, as demonstrated by glomerulosclerosis, proteinuria, and increase in creatinine which reflects a diminished glomerular filtration rate ([21], and El-Meanawy, unpublished data). The Os mutation produces a similar renal phenotype when bred on other genetic backgrounds, such as $\mathrm{FvB}$ and $\mathrm{C} 3 \mathrm{H}$ [20,22-24]. However, a congenic mouse strain, the $\mathrm{C} 57 \mathrm{Bl} / 6 \mathrm{~J}-\mathrm{Os} /+(\mathrm{C} 57-\mathrm{Os} /+)$, which has the Os mutation on a $\mathrm{C} 57 \mathrm{Bl} / 6 \mathrm{~J}$ background, develops oligosyndactyly and oligomeganephronia but not FSGS [22], thus providing an ideal model for transcriptome comparison with the ROP-Os/+ mouse.

SAGE captures an unbiased, quantitative snapshot of gene expression patterns [25-27]. SAGE libraries are comprised of cDNA sequence tags derived from the 3' end of the cDNA pool, and a count of SAGE-derived cDNA tags provides a quantitative representation of the corresponding mRNAs in the sample. We previously used SAGE to generate a tag library from normal mouse kidney, which yielded a potassium channel not known to be expressed in the kidney $[28,29]$. In the current report, we exploited phenotypic differences between the sclerosis-prone ROP-Os/+ and the sclerosis-resistant C57-Os/+ mice to discover candidate FSGS susceptibility and/or protective genes by comparing the kidney transcriptomes between the two mouse strains using SAGE. To identify pathophysiologically relevant genes, we specifically examined transcriptome profiles in young mice after completion of nephrogenesis, but prior to the development of significant FSGS. Statistical analysis of the SAGE libraries from ROP-Os/+ and C57-Os/+ mice kidneys, followed by assembly of differentially expressed transcripts into networks, allowed identification of genes which potentially play a role in the pathogenesis of glomerulosclerosis in the Os mouse model.

\section{Methods}

\section{Animals and tissue collection}

Animal experiments were conducted in accordance with the National Institute of Health guidelines and approved by the Institutional Animal Care and Utilization committee at Case Western Reserve University and the Medical College of Wisconsin. ROP-Os/+ and C57-Os/+ mice were purchased from Jackson Laboratories (Bar Harbor, ME) and housed in the animal facilities at the above institutions. We phenotyped mice at 6,10,12, and 16 weeks by comparing urine protein to creatinine ratio, glomerular surface area, and sclerosis score in Periodic Acid Schiff (PAS) stained sections as previously described [30]. Glomerular number was determined by the maceration method as previously described [31]. The kidneys were collected for SAGE library construction at 6 weeks of age to avoid identification of developmental genes (because mouse nephrogenesis continues up to 4 weeks of age), and prior to the onset of significant renal disease. After sacrifice, the kidneys were promptly removed and the renal medulla was dissected away and discarded. A small portion of each kidney was fixed in formaldehyde, sectioned, and stained with PAS for histopathological analysis.

\section{Generation of SAGE libraries}

Poly $(\mathrm{A})^{+}$RNA was isolated from renal cortices of ROP-Os/+ and $\mathrm{C} 57 \mathrm{Bl} / 6-\mathrm{Os} /+$ mice using ion-exchange column kits from Qiagen (Valencia, CA). The quality of the isolated RNA was analyzed by agarose gel electrophoresis and RNA concentration was determined by UV spectrophotometry [32]. RNA from three mice per strain was pooled and cDNA was synthesized from a starting amount of $5 \mu \mathrm{g}$ poly(A) ${ }^{+}$ RNA using cDNA synthesis kit, according to manufacturer recommendation (Invitrogen). A fraction of first and second strand reactions was labeled with $\left[{ }^{32} \mathrm{P}\right]$ to evaluate synthesis efficiency. cDNA quality was assessed using agarose gel electrophoresis and by measuring radioisotope incorporation. SAGE steps were performed as described previously [29] 
using the restriction endonuclease Nla-III as the anchoring enzyme [29]. We used SAGE software to analyze the SAGE produced concatemer sequences, which identifies the cDNA tags flanked by Nla-III restriction enzyme recognition sequence. In addition, the software identifies and excludes duplicate ditags, which are likely to be PCR amplification artifacts. Confirmation of SAGE tag gene identity, as well as relative expression levels were performed using northern blots, RNase protection assay or real-time RT-PCR. The confirmatory methods and data are in a Additional file 1.

\section{Statistical analysis of SAGE tags}

We applied several statistical models, which employ Bayesian methods or Poisson distributions, to identify tags that were significantly different between the ROP-Os/+ and C57-Os/+ kidney libraries [33-36]. The method allows comparison of unequal libraries based on the assumption that tag counts are binomially distributed. Regardless of the method used to identify statistically significant differentially expressed tags, rank orders and p-values were comparable.

\section{Annotation of SAGE tags}

Accurate annotation of SAGE tag libraries requires a combination of methods. Accordingly, we used multiple approaches to annotate SAGE tags including the online engine "SAGE genie" (http://cgap.nci.nih.gov/SAGE/ mSEM), and manual nucleotide blast (blastn) searches. We also constructed genome-wide mouse cDNA data sets from NCBI-Ref-Seq and Riken-Fantom collections and designed a software program, which identifies and catalogues the 3'-most "CATG" sequence string (Nla-III recognition sequence) with the 3' flanking 10 nucleotides. These tag-to-gene database tables were used to annotate the SAGE tags. Ambiguous tags, which mapped to multiple genes, and single copy tags were excluded. Tags were assigned gene identifiers if the tag mapped to a sequence that contained the most 3'-CATG sequence. Sequence databases were searched in the following priority: 1) our own libraries containing tags extracted from Ref-Seq and Fantom cDNA databases; 2) the mouse mSAGE expression matrix using SAGE Genie; or 3 ) the mouse mRNA (non-redundant [nr] and expressed sequence tags [dbest]) databases using blastn.

\section{Assembly of transcriptome networks and pathways}

We utilized the Ingenuity Pathway Analysis (IPA) system (Ingenuity Systems, Mountain View, CA, USA, www. ingenuity.com) to visualize the SAGE data as biological networks. To perform a "connectivity" analysis, a table containing selected gene identifiers, defined as Focus Genes, and their corresponding relative mRNA expression ratios between ROP-Os/+ and C57-Os/+ kidneys was uploaded into the application. Criteria for selection as Focus Genes included: 1) a greater than 2-fold difference in expression levels between the ROP-Os/+ and C57-Os/+ kidney libraries; and/or 2) a p-value $<0.05$ for differential expression after correction for multiple testing. Three hundred and nine genes met these criteria, were mapped to their corresponding gene objects in the Ingenuity Pathway Knowledge Base and subsequently overlaid onto a global molecular network developed from information contained in Ingenuity Pathways Knowledge Base. Networks were then algorithmically generated based on the connectivity of the eligible genes. Twenty-eight Focus Genes failed to generate a shared molecular network or pathway. Function of the connectivity networks was inferred from the functions of the genes in the network as annotated in the Knowledge Base.

An additional set of networks was generated using the functional information in the Ingenuity Pathways Knowledge Base ("functional" analysis). Genes from the SAGE kidney libraries, which met the cutoffs defined above and that were associated with biological functions in the Ingenuity Pathways Knowledge Base, were considered for this analysis. Right-tailed Fisher's exact test was used to calculate a p-value reflecting the probability that each biological function assigned to that network is due to chance alone. Networks were ranked according to the combinatorial p-value of differentially expressed genes represented in the network.

\section{TGF $\beta$ Western blot analysis}

Western blot of kidney protein extracts were performed as previously described [37] using TGF $\beta$ specific antibody. Equal loading was verified by stripping the membrane and probing for actin expression.

\section{TGF $\beta$ assay}

TGF $\beta$ activity was determined using mink lung epithelial cells expressing the firefly luciferase reporter gene under the control of the minimal, TGF $\beta$-responsive, plasminogen activator inhibitor-1 (PAI-1) promoter [38] (gift from Dr. Daniel Rifkin, New York University). The culture conditions were as previously described [39]. The effect of Itch overexpression on TGF $\beta$ was determined from two nearly confluent six-well tissue culture plates, which were transiently transfected with either mouse Itch cDNA which was cloned in pCDNA3.1 or empty vector control, using lipofectamine (Invitrogen) according to manufacturer recommendations. Twenty-four hours after transfection, TGF $\beta$ (R\&D system) was added to the culture media at $200 \mathrm{ng} / \mathrm{ml}$. The cultures were maintained for $8 \mathrm{~h}$ and luciferase activity was assayed using a Promega kit according to manufacturer instructions. Relative luminescence units were determined 
compared to control conditions (empty pCDNA3.1 plasmid transfected cells).

\section{Comparing differentially expressed Os mice genes to human FSGS expression data}

We compared 40 SAGE-derived transcripts with the most divergent expression levels between ROP-Os/+ versus C57-Os/+ kidneys, with the human microarray expression data, comprised of samples obtained from micro-dissected human kidney biopsies from patients with FSGS [40]. The fold change and significance (assessed by q-value, corrected for multiple testing) was calculated by the Significance Analysis of Microarrays method (SAM) [41] using the MeV software from the Institute of Genome Research (www.jcvi.org).

\section{Identification of glomerular enriched genes in the Os model of FSGS}

To identify genes which are differentially expressed in our model system, and are known to be expressed in the glomerulus, we searched for common genes between the glombase [42] gene list, SAGE glomerular tags [43] and annotated transcripts with the most significant differential expression between ROP-Os/+ versus C57-Os/+ kidneys. We then used Pubmed and Ingenuity pathway analysis to mine the literature for possible links between these genes and nephropathy.

\section{Results}

\section{Mouse phenotype}

We found that the urine protein to creatinine ratio was significantly higher in ROP-Os/+ mice compared to both C57-Os/+ and ROP-+/+ at all time points. The proteinuria in ROP-Os/+ mice reached a peak at 12 weeks. The glomerular surface area at 6 weeks was similar between the ROP-Os/+ and C57-Os/+ (5646 \pm 286 and $5708 \pm$ $460 \mu^{2}$, respectively) and significantly larger than glomerular surface area of ROP-+/+ $\left(3984 \pm 456 \mu \mathrm{m}^{2}\right)$. However, by 16 weeks of age, the surface area had increased significantly in the ROP-Os/+ compared to C57-Os/+glomeruli $\left(8990 \pm 628\right.$ vs $\left.6458 \pm 1259 \mu \mathrm{m}^{2}\right)$. Furthermore, the ROP-Os/+ mice showed progressive increase in sclerosis score over time (Additional file 1).

\section{Os/+ kidney SAGE libraries}

We constructed SAGE libraries from renal cortical RNA extracted from ROP-Os/+ and C57-Os/+ kidneys at 6 weeks of age (Table 1), a time point which permitted completion of differentiation, but prior to observation of significant glomerulosclerosis. The combined ROP-Os/+ and C57-Os/+ kidney SAGE libraries contained 49,588 cDNA sequence tags, of which 20,594 were unique. We did not observe "loss of AT-rich tags" bias [44] and the libraries demonstrated $54.32 \% \mathrm{~A}+\mathrm{T}$ and $45.68 \% \mathrm{C}+\mathrm{G}$
Table 1 SAGE tag counts

\begin{tabular}{lcc}
\hline & C57-Os/+ & ROP-Os/+ \\
\hline Total tags & 26599 & 22989 \\
Unique tags & 11014 & 9580 \\
\hline $\begin{array}{l}\text { The statistical analysis algorithm normalizes the tag representation in each } \\
\text { library, based on the total number of tags per library. Duplicate ditags and } \\
\text { tags that contained linker sequence were excluded from the analysis. }\end{array}$
\end{tabular}

nucleotides. Table 2 shows the 50 most statistically significant, differentially expressed and annotated tags. We compared the annotated genes in our SAGE libraries to publically available wild type mouse Nla-III-anchored SAGE libraries. Of the genes not previously described in SAGE kidney libraries, we observed significant expression of arginine-glutamic acid dipeptide (RE) repeats (Rere or Atrophin-2), insulin-like growth factor binding protein $(I g f b p 7)$, aminolevulinic acid synthase (Alas 1$)$, glutathione S-transferase, theta 1 (Gstt1), and propionyl coenzyme A carboxylase $(P c c b)$. Interestingly, all of these transcripts were induced to a detectable level in ROP-Os/+, suggesting that deep SAGE coverage can unmask changes in kidney gene expression patterns induced in a disease model. To identify differentially expressed glomerular genes, we searched for common genes between glombase [42], SAGE glomerular tags [43] and 220 annotated transcripts with the most significant differential expression between ROP-Os/+ versus C57-Os/+ kidneys. This comparison yielded 67 genes, of which 53 were upregulated, and only 14 were downregulated in the ROP-Os/+ mouse (Table 3). We confirmed a reduction in glomerular number in 6 week old ROP-Os/+ mice (data not shown), suggesting that upregulated gene expression is not due to altered glomerular mass.

\section{Assembly of differentially expressed networks and pathways}

Using the Ingenuity Pathway Analysis software to perform a connectivity analysis (see Methods), we identified multiple molecular networks of genes differentially expressed in ROP-Os/+ and C57-Os/+ kidneys. These interactions are developed from published literature describing either physical or functional interactions between the molecules. The 13 most significant gene networks, based on connectivity and their imputed molecular and cellular functions, are shown in Table 4; corresponding diagrams of the actual connectivity networks are shown in Figure 1 and the supplemental data (Additional file 1).

Because TGF $\beta$ has been implicated in the pathogenesis of glomerulosclerosis, we next chose to overlay the canonical TGF $\beta$ signaling network onto our connectivity networks. TGF $\beta 1$ signaling pathway target genes, $H n f 4 a$, Itch, and Map3K7ip1, were upregulated in the ROP-Os/+ kidneys, in agreement with published microarray analysis of laser-captured/microdissected human glomeruli from 
Table 2 Top 50 differentially expressed tags between ROP-Os/+ and C57-Os/+kidneys

\begin{tabular}{|c|c|c|c|c|c|}
\hline TAG & ROP-Os & C57-Os & P-Value & Gene Symbol & Gene Name \\
\hline CTATCCTCTC & 873 & 613 & 1.47E-10 & Gpx3 & Glutathione peroxidase 3 \\
\hline ATTAACTTGG & 54 & 14 & $75 \mathrm{E}-06$ & Glud1 & Glutamate dehydrogenase 1 \\
\hline TGGTTGCTGG & 8 & 42 & $2.53 \mathrm{E}-05$ & Nrp2b & Neuropilin2b \\
\hline TCAAAAAAAA & 15 & 0 & 0.000115878 & Pea15 & Phosphoprotein enriched in astrocytes 15 \\
\hline ACAAAAAAAA & 20 & 2 & 0.000138392 & Pde6c & Phosphodiesterase 6C, cGMP specific, cone, alpha prime \\
\hline AACTTGATTA & 14 & 0 & 0.000237608 & Ndufa12 & NADH dehydrogenase (ubiquinone) 1 alpha subcomplex, 12 \\
\hline GTTCACTTTC & 27 & 6 & 0.000390333 & Atp5e & ATP synthase, $\mathrm{H}+$ transporting, mitochondrial F1 complex, epsilon subunit \\
\hline CTGCTGTAAT & 15 & 2 & 0.000577048 & Aspm & Asp (abnormal spindle)-like, microcephaly associated (Drosophila) \\
\hline TGTTGTGTTT & 0 & 15 & 0.000858214 & Lman2l & Lectin, mannose-binding 2-like \\
\hline GTGAGCCCAT & 0 & 14 & 0.001280824 & Hsp90ab1 & Heat shock protein 90 kDa alpha (cytosolic), class B member 1 \\
\hline GCCACGCCCC & 24 & 6 & 0.001296626 & Hpd & 4-hydroxyphenylpyruvic acid dioxygenase \\
\hline ATTCTCCAGT & 14 & 39 & 0.0017137 & Rpl23 & Ribosomal protein $L 32$ \\
\hline GTCCTGAGAG & 9 & 0 & 0.002106134 & Vamp8 & Vesicle-associated membrane protein 8 \\
\hline ATAAAAAAAA & 9 & 0 & 0.002106134 & Bag4 & BCL2-associated athanogene 4 \\
\hline ATTCTAACAT & 15 & 2 & 0.002151531 & Acadm & Acyl-Coenzyme A dehydrogenase, medium chain \\
\hline TGGATGCCTT & 1 & 16 & 0.002228166 & Adh1 & Alcohol dehydrogenase \\
\hline GATTCCGTGA & 1 & 4 & 0.002494576 & Rpl37 & Ribosomal protein $\mathrm{L} 37$ \\
\hline GCTITGAATG & 19 & 4 & 0.002494576 & Atpif1 & ATPase inhibitory factor 1 \\
\hline TGTCATCTAG & 6 & 30 & 0.000282 & Rpsa & Ribosomal protein SA (laminin receptor like 1) \\
\hline TGCTGCTCCC & 0 & 12 & 0.00287027 & Gyk & Glycerol kinase \\
\hline GCTGGCCTCC & 1 & 15 & 0.003314916 & Rhoq & Ras homolog gene family, member $\mathrm{Q}$ \\
\hline GCCAAGTGGA & 22 & 6 & 0.0041826 & Eef2 & Eukaryotic translation elongation factor 2 \\
\hline GTTTGTAAAA & 22 & 6 & 0.0041826 & Acsm3 & Acyl-CoA synthetase medium-chain family member 3 \\
\hline AGATAACACA & 8 & 0 & 0.004417209 & Rere (atrophin-2) & Arginine glutamic acid dipeptide (RE) repeats \\
\hline AAGACCTATG & 39 & 17 & 0.004902036 & Dbi & Diazepam binding inhibitor \\
\hline ATCCGATTCC & 11 & 31 & 0.005368014 & Miox & myo-inositol oxygenase \\
\hline GTCAATGACG & 1 & 13 & 0.007371123 & Aqp1 & Aquaporin1 \\
\hline TCAGGCTGCC & 180 & 130 & 0.008291421 & Fth1 & Ferritin heavy chain 1 \\
\hline TTGTTAGTGC & 36 & 66 & 0.008331722 & Mdh1 & Malate dehydrogenase 1 \\
\hline CTAGTCTTTG & 22 & 7 & 0.008750438 & $\operatorname{Rps} 29$ & Ribosomal protein S29 \\
\hline CTGCTGTGGA & 22 & 7 & 0.008750438 & Hmgcs2 & 3-hydroxy-3-methylglutaryl-Coenzyme A synthase 2 \\
\hline AGAGACAAGG & 46 & 23 & 0.008962126 & Ndrg1 & $\mathrm{N}$-myc downstream regulated gene 1 \\
\hline GATCAGAAAA & 7 & 0 & 0.009358827 & Prdm16 & PR domain containing 16 \\
\hline GTGTGATACA & 7 & 0 & 0.009358827 & Pccb & propionyl Coenzyme A carboxylase, beta polypeptide \\
\hline CAGTTGGTTC & 7 & 0 & 0.009358827 & Mm.399814 & Transcribed locus \\
\hline CAGTAAAAAA & 7 & 0 & 0.009358827 & Map3k7ip1 & Mitogen-activated protein kinase kinasekinase 7interacting protein 1 \\
\hline AACTTTTAAA & 7 & 0 & 0.009358827 & Hp1bp3 & Heterochromatin protein 1, binding protein 3 \\
\hline GCTGTATTCA & 7 & 0 & 0.009358827 & Folh1 & Folate hydrolase \\
\hline AATAAAAACT & 7 & 0 & 0.009358827 & FBXL12 & F-box and leucine-rich repeat protein 12 \\
\hline TITGTGACTG & 7 & 0 & 0.009358827 & Ctbp1 & C-terminal binding protein 1 \\
\hline AGATCTGCCC & 7 & 0 & 0.009358827 & Atp6v1g1 & ATPase, $\mathrm{H}+$ transporting, lysosomal V1 subunit G1 \\
\hline CTGCGGGTCT & 7 & 0 & 0.009358827 & Angptl7 & Angiopoietin-like 7 \\
\hline GACCGTCTCA & 0 & 9 & 0.0098287 & Slc4a4 & Solute carrier family 4 (anion exchanger), member 4 \\
\hline TTGGACTGAG & 0 & 9 & 0.0098287 & Gabarapl2 & Gamma-aminobutyric acid (GABA-A) receptorassociated protein-like 2 \\
\hline
\end{tabular}


Table 2 Top 50 differentially expressed tags between ROP-Os/+ and C57-Os/+kidneys (Continued)

\begin{tabular}{lrrlll}
\hline TGATTITGAA & 9 & 1 & 0.01011074 & Por & P450 (cytochrome) oxidoreductase \\
GAGACTAGCA & 3 & 15 & 0.010247643 & Tspan3 & Tetraspanin 3 \\
GTCGTGCCAT & 14 & 33 & 0.010481768 & Nudt19 & Nudix (nucleoside diphosphate linked moiety X)-typemotif 19 \\
TGAGGGGAGC & 1 & 12 & 0.011021395 & Flrt2 & Fibronectin leucine rich transmembraneprotein 2 \\
TGCCCCCTCC & 1 & 12 & 0.011021395 & Cgnl1 & Cingulin-like 1 \\
TAGCTTTAAA & 74 & 45 & 0.011671747 & lgfbp7 & Insulin-like growth factor binding protein 7 \\
\hline
\end{tabular}

Mitochondrial, unknown, and ambiguous tags (those that match multiple genes) were excluded from the analysis.

FSGS biopsies [45]. Overlaying TGF $\beta 1$-regulated signaling pathways on to the connectivity networks of differentially expressed genes demonstrated that directional changes in gene expression patterns (up or down) in multiple networks $(1,2,6,8$, and 13) could be a result of TGF $\beta 1$ signaling. Figure 2 shows molecular network 1 (Table 4) with the TGF $\beta$ signature identified.

We also performed a functional analysis using the Ingenuity Pathway Analysis system (see Methods). These data demonstrated functional clustering of differentially expressed genes within known canonical pathways, and highlighted mitochondrial dysfunction and oxidative stress responses as mechanisms for disease (Figure 2). Interestingly, a Nrf2-dependent stress response, which is the target for a new class of diabetic nephropathy drug [46], appears to also be activated in ROP-Os/+ kidneys.

Surprisingly, TGF $\beta$ Tag was not differentially expressed between the sclerotic and non-sclerotic kidneys. Because the pathway analyses identified a prominent role for TGF $\beta$ in ROP-Os/+-dependent FSGS pathogenesis, we there fore compared TGF $\beta$ proteinbetween ROP-Os/+ and C57-Os/+ kidneys using Western blot analysis, and found no significant difference between the two strains (Figure 3).

\section{Itch overexpression increases sensitivity to TGF $\beta$ invitro}

To test the involvement of TGF $\beta$-related candidate genes in glomerular fibrogenesis, we evaluated the effect of Itch, which was upregulated in ROP-Os/+ kidneys, on TGF $\beta$ signaling. This gene was selected because Itch, an E3 ubiquitin ligase, amplifies TGF $\beta$ signaling by facilitating the interaction between the TGF $\beta$ receptor and SMAD2 [47]. For these experiments we used mink lung epithelial cells which express the firefly luciferase under the control of minimal TGF $\beta$-responsive PAI-1 promoter [38]. As seen in Figure 4 cells transfected with Itch cDNA showed higher luciferase activity in response to TGF $\beta$, compared to control cells transfected with empty vector, suggesting that enhanced Itch expression may be relevant to the ROP-Os/+ phenotype by stimulating TGF $\beta$ signaling.

\section{Differentially expressed genes in murine FSGS are similarly regulated in human FSGS}

To determine if the comparative transcriptome analysis illuminated changes in gene expression in human FSGS, we compared the 40 most significant, differentially expressed genes derived from the ROP-Os/+ vs. C57-Os/+ analysis, with microarray data from kidney biopsy samples derived from patients with FSGS [48]. Of the 40 queried genes, corresponding oligonucleotides from six (ACSM2A, TSPAN33, ERRFI1, NDUFA12, TMEM27, and RHPN2) were not spotted on the array chip. Of the remaining 34 genes, 17 were concordantly regulated in the human glomerulus and ROP-Os/+ mouse kidney, and altered mRNA expression in the human samples was statistically significant for 13 of the 17 genes. Two of the 13 genes were also concordantly regulated in the human tubulointerstitium and ROP-Os/+ mouse kidney (Table 5). An additional concordantly regulated gene, ID2, which encodes inhibitor of DNA binding 2, localized exclusively to the human tubulointerstitium.

\section{Discussion}

Focal and segmental glomerulosclerosis is the histopathologic pattern of a spectrum of renal diseases which start with the glomerulus. There exists the likelihood that multiple insults converge on a common pathogenic pathway. Monogenic forms of familial FSGS due to mutations in TRPC6, $\alpha$-actinin-4, podocin or APOL1 have been previously described $[15,16,49]$. To identify novel, candidate FSGS susceptibility genes, we compared SAGE-generated kidney transcriptomes from ROP-Os/+ and $\mathrm{C} 57-\mathrm{Os} /+$ mouse strains that are glomerulosclerosissusceptible and resistant, respectively. Both strains carry the Os mutation which causes reduction in nephron number. The quantitative decrease in nephron number is similar between the two strains, however, the C57-Os/+ strain is protected against the development of renal disease $[22,50]$. The glomerulosclerosis phenotype that is associated with the Os-induced reduction in nephron number has been shown in other strains, but it appears the C57-BL/6 genetic background is unique in its resistance to glomerulosclerosis $[23,24]$. The increase in glomerular surface area in the ROP-Os/+ strain reflects a hyperfiltration physiology which appear to be not as prominent in the C57-Os/+ strain. Comparison between the ROP-Os/+ and C57-Os/+ transcriptome is therefore a useful approach to identify potential nephropathy genes. 
Table 3 Genes which are differentially expressed between ROP-Os/+ and C57-Os/+ which have been shown to be expressed in the glomerulus

\begin{tabular}{|c|c|c|c|}
\hline Gene symbol & ROP-Os & C57-Os & P-Value \\
\hline Glud1 & 54 & 14 & $2.7461 \mathrm{E}-06$ \\
\hline Pea15 & 15 & 0 & 0.000115878 \\
\hline Aspm & 15 & 1 & 0.000577048 \\
\hline Hsp90ab1 & 0 & 14 & 0.001280824 \\
\hline Rpl23 & 14 & 39 & 0.0017137 \\
\hline Atpif1 & 19 & 4 & 0.002494576 \\
\hline Rpl37 & 19 & 4 & 0.002494576 \\
\hline Aqp1 & 1 & 13 & 0.007371123 \\
\hline Mdh1 & 36 & 66 & 0.008331722 \\
\hline Ndrg1 & 46 & 23 & 0.008962126 \\
\hline Atp6v1g1 & 7 & 0 & 0.009358827 \\
\hline Ctbp1 & 7 & 0 & 0.009358827 \\
\hline Nudt19 & 14 & 33 & 0.010481768 \\
\hline Cgnl1 & 1 & 12 & 0.011021395 \\
\hline lgfbp7 & 74 & 45 & 0.011671747 \\
\hline Cox6c & 39 & 19 & 0.012221381 \\
\hline Cox4i1 & 26 & 10 & 0.012316032 \\
\hline$D d \times 5$ & 27 & 11 & 0.013319653 \\
\hline Psap & 53 & 30 & 0.018772506 \\
\hline Agps & 5 & 0 & 0.020110086 \\
\hline Dpep1 & 5 & 0 & 0.020110086 \\
\hline Prdx6 & 5 & 0 & 0.020110086 \\
\hline Tmsb4x & 5 & 0 & 0.020110086 \\
\hline Tufm & 5 & 0 & 0.020110086 \\
\hline Uqcrh & 5 & 0 & 0.020110086 \\
\hline Pdzk1ip1 & 7 & 20 & 0.022573009 \\
\hline Mdh2 & 12 & 3 & 0.022949534 \\
\hline Sod1 & 12 & 3 & 0.022949534 \\
\hline ld 2 & 3 & 12 & 0.032439845 \\
\hline Sdf4 & 0 & 6 & 0.035034341 \\
\hline Tns1 & 14 & 14 & 0.037827945 \\
\hline Herpud1 & 16 & 6 & 0.038419946 \\
\hline Ttr 16 & 16 & 6 & 0.038419946 \\
\hline Prdx1 & 5 & 16 & 0.041379494 \\
\hline Calm2 & 11 & 3 & 0.042872521 \\
\hline Rps28 & 11 & 3 & 0.042872521 \\
\hline Slc25a3 & 14 & 28 & 0.042939254 \\
\hline Ankhd1 & 7 & 1 & 0.043285935 \\
\hline Fech 7 & 7 & 1 & 0.043521115 \\
\hline Tmem111 & 7 & 1 & 0.043285935 \\
\hline Gnb2 & 7 & 18 & 0.043285935 \\
\hline Abhd3 & 4 & 0 & 0.044128269 \\
\hline
\end{tabular}

Table 3 Genes which are differentially expressed between ROP-Os/+ and C57-Os/+ which have been shown to be expressed in the glomerulus (Continued)

\begin{tabular}{|c|c|c|c|}
\hline Acad9 & 4 & 0 & 0.044128269 \\
\hline Aig1 & 4 & 0 & 0.044128269 \\
\hline Atp6ap1 & 4 & 0 & 0.044128269 \\
\hline B3gat3 & 4 & 0 & 0.044128269 \\
\hline Cct4 & 4 & 0 & 0.044128269 \\
\hline Cited2 & 4 & 0 & 0.044128269 \\
\hline Creld1 & 4 & 0 & 0.044128269 \\
\hline Ctgf & 4 & 0 & 0.044128269 \\
\hline Fads2 & 4 & 0 & 0.044128269 \\
\hline Fkbp2 & 4 & 0 & 0.044128269 \\
\hline HNMT & 4 & 0 & 0.044128269 \\
\hline |tgb1 & 4 & 0 & 0.044128269 \\
\hline Kctd2 & 4 & 0 & 0.044128269 \\
\hline Mcl1 & 4 & 0 & 0.044128269 \\
\hline Mknk2 & 4 & 0 & 0.044128269 \\
\hline Mpdu1 & 4 & 0 & 0.044128269 \\
\hline Nucb1 & 4 & 0 & 0.044128269 \\
\hline Pmm1 & 4 & 0 & 0.044128269 \\
\hline Ptger4 & 4 & 0 & 0.044128269 \\
\hline Rab24 & 4 & 0 & 0.044128269 \\
\hline Sbf1 & 4 & 0 & 0.044128269 \\
\hline Scpep1 & 4 & 0 & 0.044128269 \\
\hline Sfrs6 & 4 & 0 & 0.044128269 \\
\hline Zdhhc8 & 4 & 0 & 0.044128269 \\
\hline Hspa5 & 3 & 11 & 0.047594628 \\
\hline
\end{tabular}

\section{Potentialcandidate nephropathy genes and pathways}

There are $>100$ potentially different expressed genes with a p-value of $<0.05$ between the mouse strains studied in this report. It is likely that the sclerosis phenotype of the ROP-Os/+ mice (or the resistance of the C57-Os/+ to sclerosis) can be attributed to the combined effect of multiple genes. The renal pathology is due to the expression pattern of these genes on top of the reduced nephron number with its consequent hyperfiltration. The FSGS phenotype is not merely due to difference in the expression of background genes, as we contrasted the wild type ROP versus C57BL/6 kidney transcriptome using microarray, and did not detect differential expression of the SAGE identified genes (data not shown).

In addition to the TGF $\beta$-related genes, which were evaluated in detail in Results, SAGE data showed that neuropilin-2 (Nrp2), which is expressed in the glomerulus and regulates vascular endothelial growth factor (Vegf) signaling [51,52], is downregulated in the sclerosis prone ROP-Os/+ mouse. Nrp2 knockout mice show progressive 


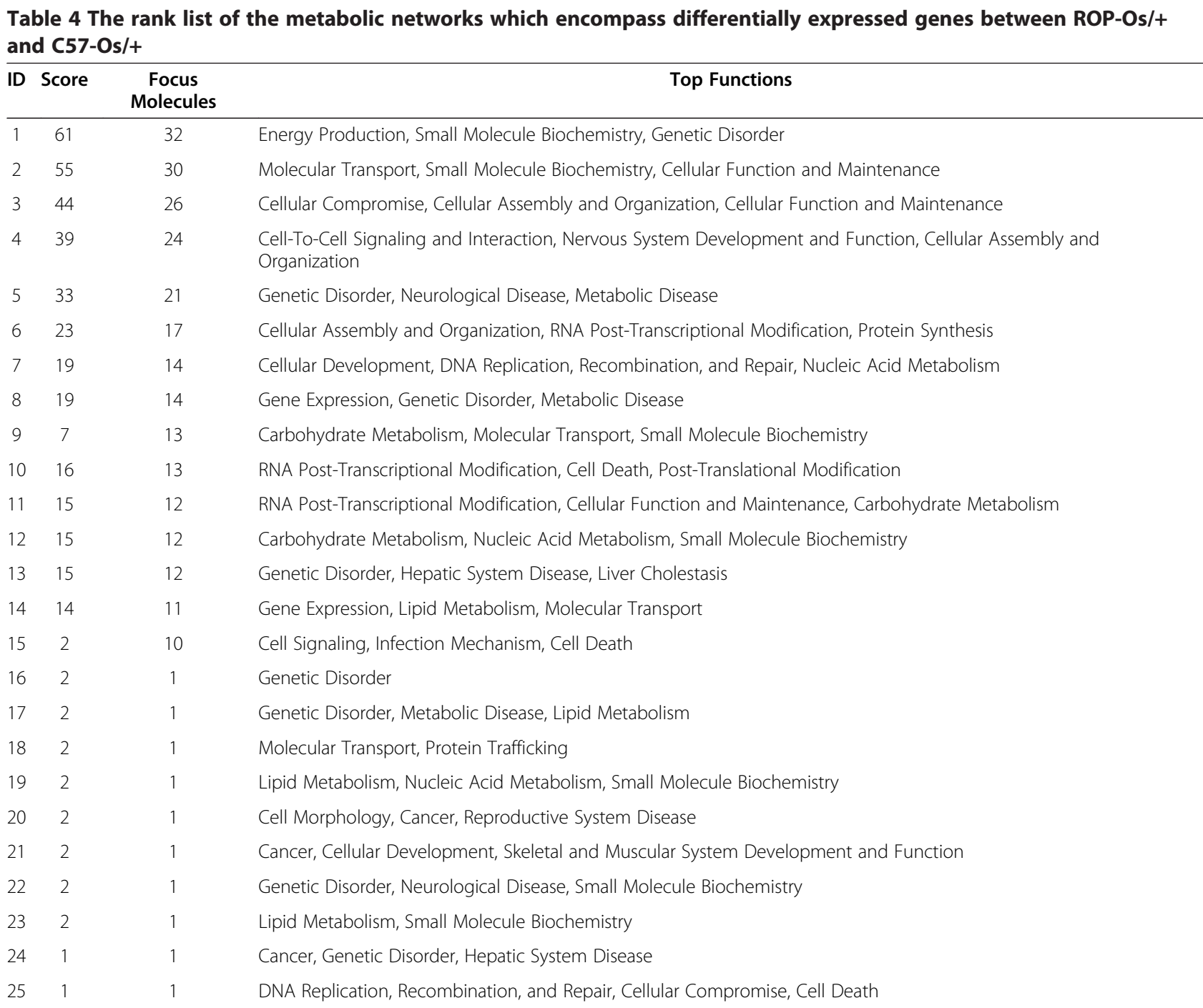

Genes from the SAGE kidney libraries, which met the 2-fold difference in expression level cut-off between ROP-Os/+ and C57-Os/+ were assigned biological functions using the Ingenuity Pathways Knowledge Base. A right-tailed Fisher's exact test was used to calculate a p-value describing the probability that each biological function assigned to that network is due to chance alone. Networks were ranked according to the combinatorial $p$-value of differentially expressed genes represented in the network. Corresponding network diagrams are shown as supplemental figures S3-S14.

glomerular damage after injection of the podocyte toxin, adriamycin, in contrast to their wild type littermates, who recover after the initial injury (J. Sedor, unpublished data).

Pea15 gene, which is overexpressed in the sclerotic mouse kidney, is a death effector domain-containing protein and promoter of autophagy. PEA15 inhibits caspase activation and increases ERK activity [53]. Transgenic mice overexpressing PEA15 have glomerular mesangial expansion and a histological pattern similar to diabetic nephropathy [54]. PEA15 induces the expression of the glucose transporter Glut1 in skeletal muscle cells [55]. Interestingly, Glut1 is also overexpressed in glomeruli from the FvB-Os/+ mice (Os mutation bred on FvB genetic background) [24], suggesting that PEA15 regulation of Glut1 may play a role in non-diabetic glomerular scarring.
In the ROP-Os/+ strain a number of ubiquitin-proteasome pathway genes are differentially expressed; Psmb5, Psma3, Fbxl12, and Itch gene expression was enhanced, while Siah1a was downregulated. The differential expression of these genes suggests a role for aberrant protein degradation in glomerulosclerosis phenotype of the $O s$ mice. Itch has been linked to the regulation of a multitude of signaling cascades, including TGF $\beta$ and EGF through ubiquitin and non-ubiquitin mediated mechanisms $[47,56]$. We tested the effect of Itch overexpression in vitro as a proof of concept that it regulates TGF $\beta$ signaling, which has been widely implicated in the pathogenesis of glomerulosclerosis. The experimental data support the hypothesis that Itch overexpression increases TGF $\beta$ signaling, independent of TGF $\beta$ ligand level (Figures 3 and 4). Itch expression is regulated by the Src 


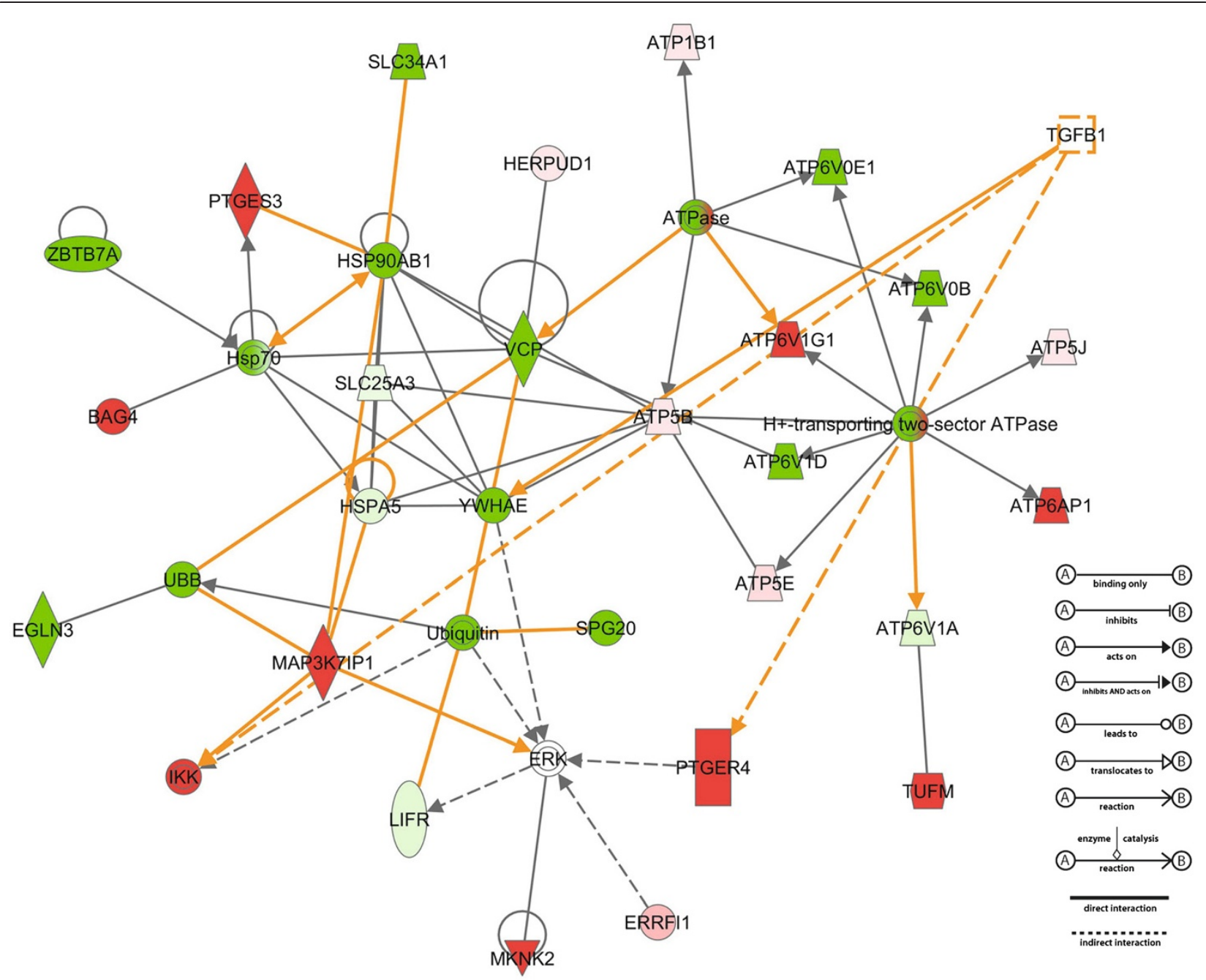

Figure 1 Ingenuity Pathway analysis generated Network 1 diagram. The networks are based on known protein-protein interactions and functional relations. Genes that are differentially expressed in the SAGE libraries are depicted in shades of red (upregulated) or green (downregulated); empty symbols represent network genes that were not differentially expressed in the SAGE libraries. TGF $\beta$ is inserted into the model to identify gene whose expression is modulated by TGF $\beta$. The diagram to the right explains the relationship lines.

kinase Fyn [57-60], which regulates podocyte function through phosphorylation of nephrin [61,62]. Bigenic Fyn/ Cd2ap heterozygotes demonstrated an FSGS phenotype [63]. Because of the links with Fyn, TGF $\beta$ and other TGF $\beta$ related signaling molecules, such as Pcbp1 [64], we speculate that Itch may function as a molecular rheostat, by regulating downstream TGF $\beta$ signaling (and FSGS pathophysiology) independent of ligand concentration.

Laser capture microdissection-microarray analysis of FSGS glomeruli demonstrated multiple changes consistent with activity of TGF $\beta$ signaling [45]. Although we did not identify differences in TGF $\beta$ ligand SAGE tag expression in our libraries, and Western blot analysis showed similar TGF $\beta$ protein expression between ROP$\mathrm{Os} /+$ and C57-Os/+ mouse kidneys, we postulate that the TGF $\beta$ pathway in the ROP-Os/+ kidney is upregulated by downstream molecules, such as Itch and SnoN.

Using the Ingenuity Pathway Analysis engine, the clustering of genes involved in oxidative stress response like the Nrf2 response genes and GPX suggests a role for an electrophile or oxidative stress in the mechanisms promoting renal injury in the ROP-Os/+ model [65]. Recently, bardoxolone methyl, which activates the Keap1Nrf2 anti-oxidant pathway, was shown to protect kidney function in patients with type 2 diabetes [46].

Genes overexpressed in the C57-Os/+ mouse may be protective. For example, glutathione-S-transferase theta (Gstt1) tag counts were 18.6 fold higher in the C57-Os/+ compared to ROP-Os/+ mice, and it was shown that the deletion of this gene increases the likelihood of ESRD in 
Mitochondrial Dysfunction

Oxidative Stress

Oxidative Stress Response Mediated by Nrf2
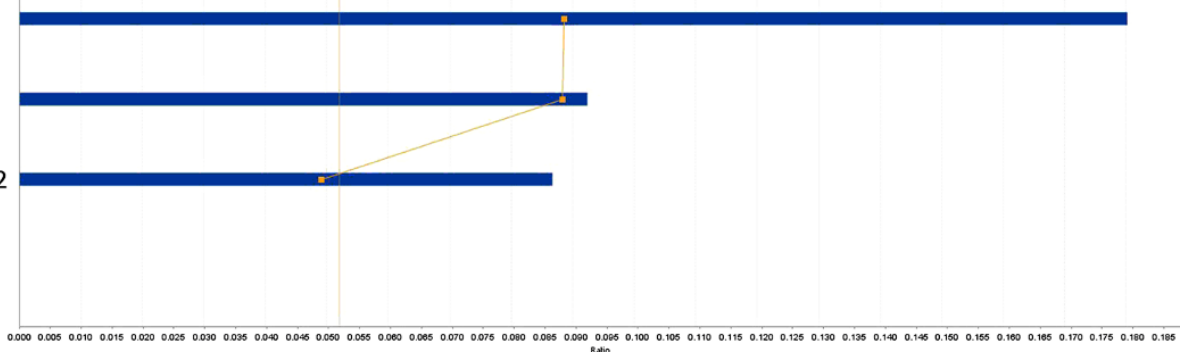

Figure 2 Ingenuity Pathway Analysis identifies canonical pathways containing SAGE differentially expressed genes. These pathways are ranked by their statistical significance (-log $p$-value) which is shown along the horizontal axis. The top three pathways are depicted in this figure, and highlight the prominence of mitochondrial dysfunction and oxidative stress genes which could potentially mediate renal injury in the ROPOs/+ mouse model.

diabetic patients [66]. Also, upregulation of Hsp90ab1, $V c p, \operatorname{Prdx1}$, and $\operatorname{Prdx} 2$ genes in the sclerosis resistant C57-Os/+ strain could indicate a robust protective response to the increased oxidative stress induced by the Os mutation.

\section{Differentially regulated genes known to be involved in renal pathology}

Connective tissue growth factor (Ctgf), integrin- $\beta 1$ (Itgb1), and secreted phosphoprotein 1 (Spp1) were all upregulated in the sclerosis-prone ROP-Os/+ mouse kidney. These genes are also upregulated in a other renal diseases characterized by fibrosis [67-72]. On the other hand, complement factor $\mathrm{H}(\mathrm{Ctf})$ and prosaposin (Psap) are relatively downregulated in ROP-Os/+ kidneys, similar to observations in membranoproliferative glomerulonephritis (MPGN) and tubular damage [73,74].

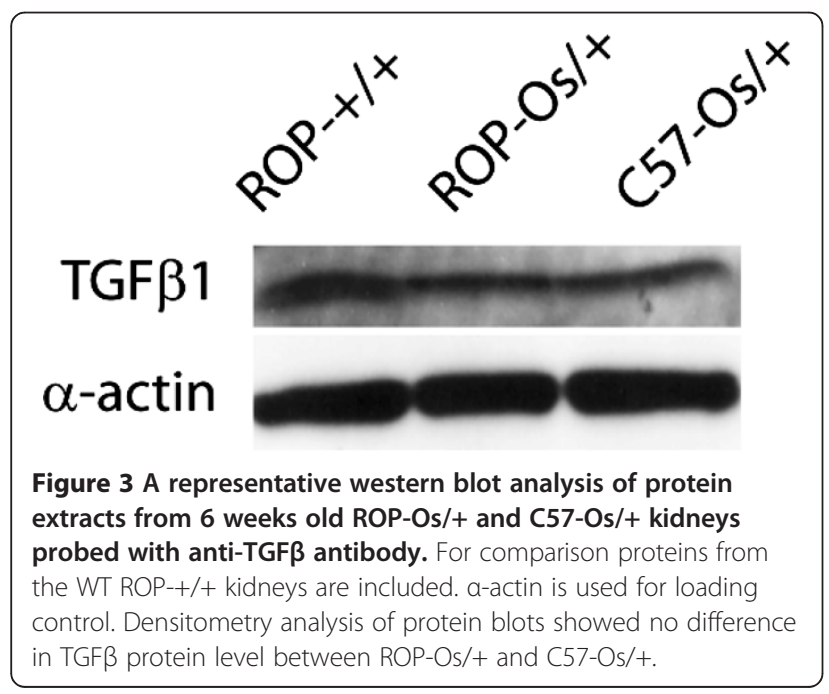

The ROP-Os/+ mouse and human FSGS

By comparing our ROP-Os/+SAGE libraries to previously published kidney SAGE libraries, we identified 13 genes, which were concordantly regulated in ROP-Os/+ kidneys and human FSGS kidney biopsies, all of which localize to the glomerulus. None of these have been previously detected using either SAGE or microarray libraries from normal kidneys, (http://www.ncbi.nlm.nih.gov/ geo/) [43,75], suggesting that novel glomerular gene sets are induced as part of the pathophysiology of FSGS. Alternatively, the regulation of gene expression in fibrotic glomeruli could be a manifestation (rather than a

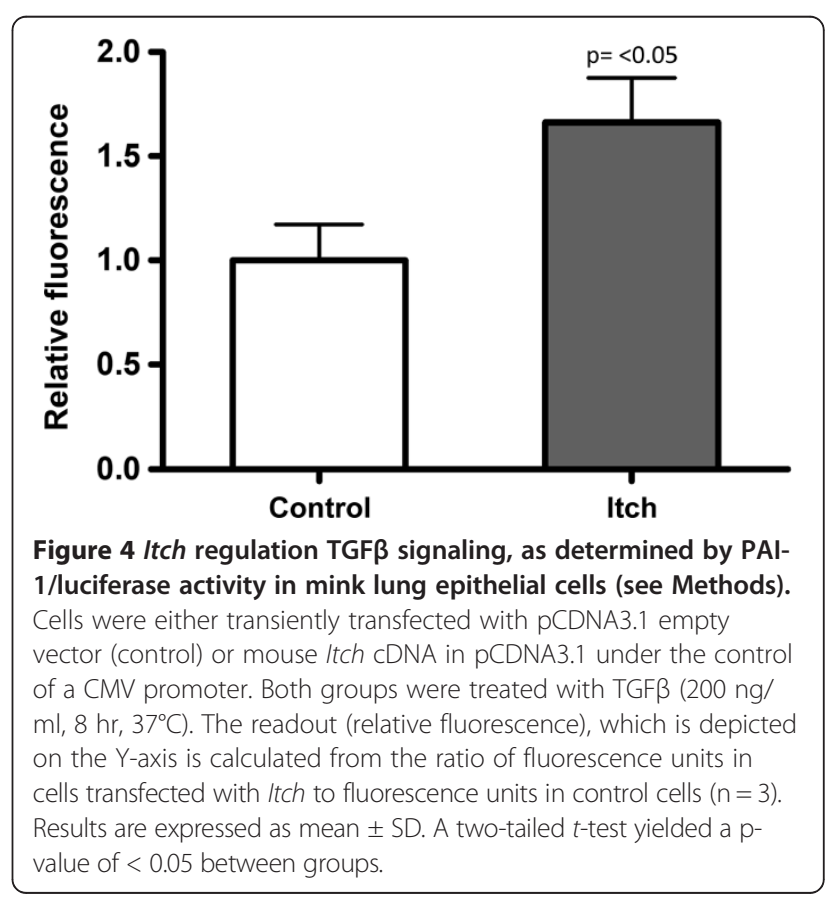


Table 5 Concordantly regulated SAGE transcripts from the ROP-Os/+ mouse model (as compared to C57-Os) and transcripts derived from microarray of human kidney biopsies from patients with FSGS (as compared to normal controls)

\begin{tabular}{|c|c|c|c|c|c|c|c|}
\hline $\begin{array}{l}\text { TAG count } \\
\text { in ROP-Os }\end{array}$ & $\begin{array}{l}\text { TAG count } \\
\text { in C57-Os }\end{array}$ & $\begin{array}{c}\text { Genes concordantly regulated } \\
\text { between mouse model and } \\
\text { human Glomerulus }\end{array}$ & $\begin{array}{l}\text { log Fold } \\
\text { Change }\end{array}$ & q-value & $\begin{array}{l}\text { Genes concordantly regulated } \\
\text { between mouse model and } \\
\text { human tubuloninterstitium }\end{array}$ & $\begin{array}{c}\text { log Fold } \\
\text { Change }\end{array}$ & q-value \\
\hline 0 & 7 & Slc 22a6 & -0.42 & 0.00 & Slc22a6 & -0.22 & 0.00 \\
\hline 0 & 9 & Slc4a4 & -0.32 & 0.00 & & & \\
\hline 1.35 & 13 & Aqp1 & -0.30 & 0.00 & & & \\
\hline 5.4 & 0 & Psmb5 & 0.21 & 0.00 & & & \\
\hline 5.4 & 0 & Pcbp1 & 0.24 & 0.00 & & & \\
\hline 5.4 & 0 & Psma3 & 0.31 & 0.00 & & & \\
\hline 6.75 & 20 & Pdzk1ip1 & -0.15 & 0.02 & & & \\
\hline 74.25 & 45 & lgfbp7 & 0.14 & 0.02 & & & \\
\hline 12.15 & 3 & Mdh2 & 0.16 & 0.02 & & & \\
\hline 9.45 & 0 & Vamp8 & 0.11 & 0.03 & & & \\
\hline 8.1 & 1 & Tmbim4 & 0.12 & 0.03 & & & \\
\hline 5.4 & 0 & Ndufb 11 & 0.21 & 0.03 & & & \\
\hline 4.05 & 16 & Lifr & -0.09 & 0.05 & Lifr & -0.27 & 0.00 \\
\hline 12.15 & 3 & Sod1 & 0.06 & 0.09 & & & \\
\hline 16.2 & 6 & Herpud1 & -0.07 & 0.14 & & & \\
\hline 2.7 & 13 & Atp6v1a & -0.03 & 0.15 & & & \\
\hline 8.1 & 42 & Nrp2b & -0.03 & 0.15 & & & \\
\hline 2.7 & 12 & & 0.11 & 0.11 & $\mathrm{Id} 2$ & -0.40 & 0.00 \\
\hline
\end{tabular}

cause) of fibrogenesis, though we attempted to minimize this possibility by selecting mice for study at an age prior to the appearance of glomerulosclerosis.

\section{Limitations of SAGE}

SAGE is a powerful tool for gene and pathway discovery. However, like other global gene expression analysis methods, it has inherent limitations. The lack of a uniform annotation tool for SAGE tags makes data analysis burdensome. Although SAGE permits assembly of a comprehensive transcriptome, the sequencing costs can be significant. As a result, most labs have resorted to microarray technology to achieve adequate, but less comprehensive coverage.

\section{Conclusions}

In this paper we have identified multiple candidate nephropathy genes which might regulate FSGS pathogenesis in a mouse model. The identified candidate genes and pathways need to be validated in knockout mice and/ or other renal disease models, in order to discover targets for rational drug design or novel renal disease susceptibility markers. The number of networks derived from the differentially expressed gene set underscores the complexity of renal disease pathogenesis, and suggests that therapies directed at multiple pathways will be needed to effectively treat human kidney diseases.

\section{Additional file}

Additional file 1: Supplemental methods, real-time PCR primers sequences, and full table of statistically significant, differentially expressed SAGE Tags (Table 2S).

\section{Competing interests}

The authors declare that they have no competing interests.

\section{Authors' contributions}

AE-M carried out phenotyping of the mice, construction and analysis of SAGE libraries, confirmation of SAGE tags, IPA analysis, TGF- $\beta$ assays, and manuscript preparation. JS participated in phenotyping, experimental design, and manuscript preparation. JS participated in phenotyping, experimental design, and manuscript preparation. SI assisted with database mining and experimental design. KG conducted statistical analysis of SAGE tags. VN and MK performed the comparative analysis of SAGE tags to human kidney disease genes. PH, SB, FP and EE participated in tag expression confirmation and SAGE tag annotation. All authors read and approved the final manuscript.

\section{Acknowledgments}

This work was supported in part by NIDDK grants 5K08DK002699 and 5T32DK007470. We acknowledge the support of the Applied Systems Biology Core of O'Brien Kidney Research Core (P30 DK081943).We thank all participating centers of the European Renal cDNA Bank - Kröner-Fresenius biopsy bank (ERCB-KFB) and their patients for their cooperation. We thank Mr. Michael Linnen (currently, at Morehead Associates) for his generous effort in developing the TAG sequence extraction software. We thank Dr. Frank Park (Medical College of Wisconsin) for his critical reading of this manuscript. 


\section{Author details}

${ }^{1}$ Department of Medicine, MetroHealth System, Case Western Reserve University, Cleveland, OH, USA. ${ }^{2}$ Department of Epidemiology and Biostatistics, Case Western Reserve University, Cleveland, OH, USA. ${ }^{3}$ Department of Medicine, University of Michigan, Ann Arbor, MI, USA

${ }^{4}$ Kidney Disease Center, Medical College of Wisconsin, Milwaukee, WI, USA.

Received: 16 December 2011 Accepted: 27 June 2012

Published: 19 July 2012

\section{References}

1. Chun MJ, Korbet SM, Schwartz MM, Lewis EJ: Focal segmental glomerulosclerosis in nephrotic adults: Presentation, prognosis, and response to therapy of the histologic variants. J Am Soc Nephrol 2004, 15:2169-2177.

2. Bakir AA, Bazilinski NG, Rhee $H L$, Ainis $H$, Dunea G: Focal segmental glomerulosclerosis. A common entity in nephrotic black adults. Arch Intern Med 1989, 149:1802-1804.

3. Bakir AA, Share DS, Levy PS, Arruda JAL, Dunea G: Focal segmental glomerulosclerosis in adult African Americans. Clin Nephrol 1996, 46:306-311.

4. Bonilla-Felix M, Parra C, Dajani T, Ferris M, Swinford RD, Portman RJ, et al: Changing patterns in the histopathology of idiopathic nephrotic syndrome in children. Kidney Int 1999, 55:1885-1890.

5. Gulati S, Sharma AP, Sharma RK, Gupta A: Changing trends of histopathology in childhood nephrotic syndrome. Amer J Kidney Dis 1999, 34:646-650.

6. Gipson DS, Trachtman H, Kaskel FJ, Greene TH, Radeva MK, Gassman JJ, et al: Clinical trial of focal segmental glomerulosclerosis in children and young adults. Kidney Int 2011, 80:868-878.

7. Fencl F, Simkova E, Vondrak K, Janda J, Chadimova M, Stejskal J, et al: Recurrence of nephrotic proteinuria in children with focal segmental glomerulosclerosis after renal transplantation treated with plasmapheresis and immunoadsorption: case reports. Transplant Proc 2007, 39:3488-3490.

8. Fine RN: Recurrence of nephrotic syndrome/focal segmental glomerulosclerosis following renal transplantation in children. Pediatr Nephrol 2007, 22:496-502.

9. Itami N, Akutus $Y$, Hattori M, Itoh K: Recurrence of nephrotic syndrome in focal segmental glomerulosclerosis after transplantation. Pediatr Nephrol 1990, 4:298-299.

10. Kaplan JM, Kim SH, North KN, Rennke H, Correia LA, Tong HQ, et al: Mutations in ACTN4, encoding à-actinin-4, cause familial focal segmental glomerulosclerosis. Nat Genet 2000, 24:251-256.

11. Winn MP, Conlon PJ, Lynn KL, Farrington MK, Creazzo T, Hawkins AF, et al: A Mutation in the TRPC6 Cation Channel Causes Familial Focal Segmental Glomerulosclerosis. Science 2005, 308:1801-1804.

12. Reiser J, Polu KR, Moller CC, Kenlan P, Altintas MM, Wei C, et al: TRPC6 is a glomerular slit diaphragm-associated channel required for normal renal function. Nat Genet 2005, 37:739-744

13. Kopp JB: Gene expression in kidney using transgenic approaches. Exp Nephrol 1997, 5:157-167.

14. Kao WH, Klag MJ, Meoni LA, Reich D, Berthier-Schaad Y, Li M, et al: MYH9 is associated with nondiabetic end-stage renal disease in African Americans. Nat Genet 2008, 40:1185-1192.

15. Genovese G, Friedman DJ, Ross MD, Lecordier L, Uzureau P, Freedman BI, et al: Association of trypanolytic ApoL1 variants with kidney disease in African Americans. Science 2010, 329:841-845.

16. Tzur S, Rosset S, Shemer R, Yudkovsky G, Selig S, Tarekegn A, et al: Missense mutations in the APOL1 gene are highly associated with end stage kidney disease risk previously attributed to the MYH9 gene. Hum Genet 2010, 128:345-350.

17. Butkus DE: Familial clustering of end-stage renal disease in Mississippi. J Miss State Med Assoc 2002, 43:71-77.

18. Magnuson T, Epstein CJ: Oligosyndactyly: a lethal mutation in the mouse that results in mitotic arrest very early in development. Cell 1984, 38:823-833.

19. Stewart AD, Stewart J: Studies on syndrome of diabetes insipidus associated with oligosyndactyly in mice. Am J Physiol 1969, 217:1191-1198.

20. He C, Zalups RK, Henderson DA, Striker GE, Striker LJ: Molecular analysis of spontaneous glomerulosclerosis in Os/+ mice, a model with reduced nephron mass. Am J Physiol 1995, 269:F266-F273.
21. Zalups RK: The Os/+ mouse: a genetic animal model of reduced renal mass. Am J Physiol 1993, 264:F53-F60.

22. Esposito C, He CJ, Striker GE, Zalups RK, Striker LJ: Nature and severity of the glomerular response to nephron reduction is strain-dependent in mice. Am J Pathol 1999, 154:891-897.

23. Lenz O, Zheng F, Vilar J, Doublier S, Lupia E, Schwedler S, et al: The inheritance of glomerulosclerosis in mice is controlled by multiple quantitative trait loci. Nephrol Dial Transplant 1998, 13:3074-3078.

24. Wang Y, Heilig KO, Minto AW, Chen S, Xiang M, Dean DA, et al: Nephrondeficient Fvb mice develop rapidly progressive renal failure and heavy albuminuria involving excess glomerular GLUT1 and VEGF. Lab Invest 2009, 90:83-97.

25. Velculescu VE, Zhang L, Vogelstein B, Kinzler KW: Serial analysis of gene expression. Science 1995, 270:484-487.

26. Velculescu VE, Madden SL, Zhang L, Lash AE, Yu J, Rago C, et al: Analysis of human transcriptomes. Nat Genet 1999, 23:387-388.

27. Velculescu VE, Zhang L, Zhou W, Vogelstein J, Basrai MA, Bassett DE Jr, et al: Characterization of the yeast transcriptome. Cell 1997, 88:243-251.

28. El-Meanawy MA, Schelling JR, Barathan S, lyengar SK, Sedor JR: Seria analysis of gene expression (SAGE). In Methods in Molecular Medicine: Renal Disease. Guide to Technical Approaches. Volume 86. 1st edition. Edited by Goligorsky MS. Totowa: The Humana Press; 2003.

29. El-Meanawy MA, Schelling JR, Pozuelo F, Churpek MM, Ficker EK, lyengar S, et al: Use of serial analysis of gene expression to generate kidney expression libraries. Am J Physiol Renal Physiol 2000, 279:F383-F392.

30. He CI, Esposito C, Phillips C, Zalups RK, Henderson DA, Striker GE, et al: Dissociation of glomerular hypertrophy, cell proliferation, and glomerulosclerosis in mouse strains heterozygous for a mutation (Os) which induces a 50\% reduction in nephron number. J Clin Invest 1996, 97:1242-1249.

31. Kaufman JM, Hardy R, Hayslett JP: Age-dependent characteristics of compensatory renal growth. Kidney Int 1975, 8:21-26.

32. Sambrook J, Fritsch EF, Maniatis T: Molecular cloning: a laboratory manual. 2nd edition. Cold Springs Harbor: Cold Springs Harbor; 1989.

33. Cooper GF, Herskovits E: A Bayesian method for the induction of probabilistic networks from data. Mach Learn 1992, 9:309-347.

34. Schoenberg BS: Calculating Confidence Intervals for Rates and Ratios. Neuroepidemiology 1983, 2:257-265.

35. van Kampen $A H$, van Schaik BD, Pauws E, Michiels EM, Ruijter JM, Caron HN, et al: USAGE: a web-based approach towards the analysis of SAGE data. Serial Analysis of Gene Expression. Bioinformatics 2000, 16:899-905.

36. Kal AJ, van Zonneveld AJ, Benes V, van den Berg M, Koerkamp MG, Albermann $\mathrm{K}$, et al: Dynamics of gene expression revealed by comparison of serial analysis of gene expression transcript profiles from yeast grown on two different carbon sources [In Process Citation]. MolBiol Cell 1999, 10:1859-1872

37. Laemmli EK: Cleavage of structural proteins during the assembly of the head of bacteriophage T4. Nature 1970, 227:680-685.

38. Abe M, Harpel JG, Metz CN, Nunes I, Loskutoff DJ, Rifkin DB: An Assay for Transforming Growth Factor-\&beta; Using Cells Transfected with a Plasminogen Activator Inhibitor-1 Promoter-Luciferase Construct. Anal Biochem 1994, 216:276-284.

39. Khan S, Lakhe-Reddy S, McCarty JH, Sorenson CM, Sheibani N, Reichardt LF, et al: Mesangial Cell Integrin [alpha]v[beta]8 Provides Glomerular Endothelial Cell Cytoprotection by Sequestering TGF-[beta] and Regulating PECAM-1. Am J Pathol 2011, 178:609-620.

40. Berthier CC, Zhang H, Schin M, Henger A, Nelson RG, Yee B, et al: Enhanced expression of Janus kinase-signal transducer and activator of transcription pathway members in human diabetic nephropathy. Diabetes 2009, 58:469-477.

41. Tusher VG, Tibshirani R, Chu G: Significance analysis of microarrays applied to the ionizing radiation response. Proc Natl Acad Sci USA 2001, 98:5116-5121.

42. He L, Sun Y, Patrakka J, Mostad P, Norlin J, Xiao Z, et al: Glomerulus-specific mRNA transcripts and proteins identified through kidney expressed sequence tag database analysis. Kidney Int 2007, 71:889-900.

43. Nystrom J, Fierlbeck W, Granqvist A, Kulak SC, Ballermann BJ: A human glomerular SAGE transcriptome database. BMC Nephrol 2009, 10:13-27.

44. Margulies EH, Kardia SL, Innis JW: Identification and prevention of a GC content bias in SAGE libraries. Nucleic Acids Res 2001, 29:E60.

45. Bennett MR, Czech KA, Arend LJ, Witte DP, Devarajan P, Potter SS: Laser Capture Microdissection-Microarray Analysis of Focal Segmental Glomerulosclerosis Glomeruli. Nephron Exp Nephrol 2007, 107:e30-e40. 
46. Pergola PE, Krauth M, Huff JW, Ferguson DA, Ruiz S, Meyer CJ, et al: Effect of bardoxolone methyl on kidney function in patients with T2D and Stage 3b-4 CKD. Am J Nephrol 2011, 33:469-476.

47. Bai Y, Yang C, Hu K, Elly C, Liu YC: Itch E3 ligase-mediated regulation of TGF-beta signaling by modulating smad2 phosphorylation. Mol Cell 2004, 15:825-831.

48. Reich HN, Tritchler D, Cattran DC, Herzenberg AM, Eichinger F, Boucherot A, et al: A Molecular Signature of Proteinuria in Glomerulonephritis. PLoS One 2010, 5:e13451.

49. Kaplan J, Pollak MR: Familial focal segmental glomerulosclerosis. Curr Opin Nephrol Hypertens 2001, 10:183-187.

50. Striker LJ: Nephron reduction in man-lessons from the Os mouse. Nephrol Dial Transplant 1998, 13:543-545.

51. Barathan S, Konieczkowski M, El-Meanawy MA, Khan S, Wang B, Dodig T, et al: Expression analysis demonstrates the cell guidance signal neuropilin $2 \mathrm{~b}$ is reduced in sclerosis-prone ROP-Os/+ but not sclerosis-resistant C57-Os/+ mouse kidneys. J Am Soc Nephrol 2001, 12:809A. Ref Type: Abstract.

52. Gluzman-Poltorak Z, Cohen T, Herzog Y, Neufeld G: Neuropilin-2 is a receptor for the vascular endothelial growth factor (VEGF) forms VEGF145 and VEGF-165. J Bio/Chem 2000, 275:29922.

53. Bock BC, Tagscherer KE, Fassl A, Kr+ñmer A, Oehme I, Zentgraf HW, et al: The PEA-15 Protein Regulates Autophagy via Activation of JNK J BiolChem 2010, 285:21644-21654.

54. Oriente F, lovino S, Cassese A, Romano C, Miele C, Troncone G, et al: Overproduction of phosphoprotein enriched in diabetes (PED) induces mesangial expansion and upregulates protein kinase C-beta activity and TGF-beta1 expression. Diabetologia 2009, 52:2642-2652.

55. Condorelli G, Vigliotta G, lavarone C, Caruso M, Tocchetti CG, Andreozzi F, et al: PED/PEA-15 gene controls glucose transport and is overexpressed in type 2 diabetes mellitus. EMBO J 1998, 17:3858-3866.

56. Omerovic J, Santangelo L, Puggioni EM-R, Marrocco J: Dall'Armi C, Palumbo $C$ et al.: The E3 ligase Aip4/Itch ubiquitinates and targets ErbB4 for degradation. The. FASEB J 2007, 21:2849-2862.

57. Azakir $B A$, Angers $A$ : Reciprocal regulation of the ubiquitin ligase Itch and the epidermal growth factor receptor signaling. Cell Signal 2009, 21:1326-1336

58. Lallemand F, Seo SR, Ferrand N, Pessah M, L'Hoste S, Rawadi G, et al: AIP4 restricts transforming growth factor-beta signaling through a ubiquitination-independent mechanism. J BiolChem 2005, 280:27645-27653.

59. Yang C, Zhou W, Jeon MS, Demydenko D, Harada Y, Zhou H, et al: Negative regulation of the E3 ubiquitin ligase itch via Fyn-mediated tyrosine phosphorylation. Mol Cell 2006, 21:135-141.

60. Magnifico A, Ettenberg S, Yang C, Mariano J, Tiwari S, Fang S, et al: WW domain HECT E3s target CbI RING finger E3s for proteasomal degradation. J Bio/Chem 2003, 278:43169-43177.

61. Verma R, Wharram B, Kovari I, Kunkel R, Nihalani D, Wary KK, et al: Fyn binds to and phosphorylates the kidney slit diaphragm component nephrin. J BiolChem 2003, 278:20716-20723.

62. Azhibekov TA, Wu Z, Padiyar A, Bruggeman LA, Simske JS: TM4SF10 and ADAP interaction in podocytes: role in Fyn activity and nephrin phosphorylation. Am J Physiol Cell Physiol 2011, 301:C1351-C1359.

63. Huber TB, Kwoh C, Wu H, Asanuma K, Godel M, Hartleben B, et al: Bigenic mouse models of focal segmental glomerulosclerosis involving pairwise interaction of CD2AP, Fyn, and synaptopodin. J Clin Invest 2006, 116:1337-1345.

64. Thiele BJ, Doller A, Kahne T, Pregla R, Hetzer R, Regitz-Zagrosek V: RNAbinding proteins heterogeneous nuclear ribonucleoprotein $A 1, E 1$, and $K$ are involved in post-transcriptional control of collagen I and III synthesis. Circ Res 2004, 95:1058-1066.

65. Nkova-Kostova AT, Liby KT, Stephenson KK, Holtzclaw WD, Gao X, Suh N, et al: Extremely potent triterpenoid inducers of the phase 2 response: correlations of protection against oxidant and inflammatory stress. Proc Natl Acad Sci USA 2005, 102:4584-4589.

66. Yang Y, Kao MT, Chang CC, Chung SY, Chen CM, Tsai JJ, et al: Glutathione S-transferase $\mathrm{T} 1$ deletion is a risk factor for developing end-stage renal disease in diabetic patients. Int J Mol Med 2004, 14:855-859.

67. Turk T, Leeuwis JW, Gray J, Torti SV, Lyons KM, Nguyen TQ, et al: BMP Signaling and Podocyte Markers Are Decreased in Human Diabetic Nephropathy in Association With CTGF Overexpression.

$J$ Histochem Cytochem 2009, 57:623-631.
68. Mason RM: Connective tissue growth factor(CCN2), a pathogenic factor in diabetic nephropathy. What does it do? How does it do it? J Cell Commun Signal 2009, 3:95-104.

69. Umezono T, Toyoda M, Kato M, Miyauchi M, Kimura M, Maruyama M, et al: Glomerular expression of CTGF, TGF-beta 1 and type IV collagen in diabetic nephropathy. J Nephrol 2006, 19:751-757.

70. Hudkins KL, Giachelli CM, Eitner F, Couser WG, Johnson RJ, Alpers CE: Osteopontin expression in human crescentic glomerulonephritis. Kidney Int 2000, 57:105-116.

71. Pichler R, Giachelli CM, Lombardi D, Pippin J, Gordon K, Alpers CE, et al: Tubulointerstitial disease in glomerulonephritis: Potential role of osteopontin (uropontin). Am J Pathol 1994, 144:915-926.

72. Mooney A, Jackson K, Bacon R, Streuli C, Edwards G, Bassuk J, et al: Type IV collagen and laminin regulate glomerular mesangial cell susceptibility to apoptosis via beta(1) integrin-mediated survival signals. Am J Pathol 1999, 155:599-606

73. Brera-Abeleda MA, Nishimura C, Smith JL, Sethi S, McRae JL, Murphy BF, et al: Variations in the complement regulatory genes factor $\mathrm{H}(\mathrm{CFH})$ and factor $\mathrm{H}$ related 5 (CFHR5) are associated with membranoproliferative glomerulonephritis type II (dense deposit disease). J Med Genet 2006, 43:582-589.

74. Matsuda J, Kido M, Tadano-Aritomi K, Ishizuka I, Tominaga K, Toida K, et al: Mutation in saposin $D$ domain of sphingolipid activator protein gene causes urinary system defects and cerebellar Purkinje cell degeneration with accumulation of hydroxy fatty acid-containing ceramide in mouse. Hum Mol Genet 2004, 13:2709-2723.

75. Lindenmeyer MT, Eichinger F, Sen K, Anders HJ, Edenhofer I, Mattinzoli D, et al: Systematic analysis of a novel human renal glomerulus-enriched gene expression dataset. PLoS One 2010, 5:e11545.

doi:10.1186/1471-2369-13-61

Cite this article as: El-Meanawy et al:: Identification of nephropathy candidate genes by comparing sclerosis-prone and sclerosis-resistant mouse strain kidney transcriptomes. BMC Nephrology 2012 13:61.

\section{Submit your next manuscript to BioMed Central and take full advantage of:}

- Convenient online submission

- Thorough peer review

- No space constraints or color figure charges

- Immediate publication on acceptance

- Inclusion in PubMed, CAS, Scopus and Google Scholar

- Research which is freely available for redistribution
C Biomed Central 